\title{
DISCUSSION
}

\section{The static compaction of soils}

\author{
B. V. VENKATARAMA REDDY and K. S. JAGADISH (1993). \\ Géotechnique 43, No. 2, 337-341
}

\section{Olivier, Ecole Nationale des Travaux Publics de l'Etat \\ In the static compression test described by} Olivier \& Mesbah (1985) the soil was compacted by quasi-static means in an oedometric mould to a compressive strength of $0.5-10 \mathrm{MPa}$. The curves obtained resemble those of the standard Proctor test (i.c. dry density plotted against moisture content). This test produces cylindrical homogeneous samples $11 \mathrm{~cm}$ in diameter and 13$16 \mathrm{~cm}$ high which can he used in simple compression and triaxial tests. It is therefore possible to study the effect of varying parameters (e.g. compaction stress, moisture content, binders and curing) on the geotechnical and mechanical properties of the compacted soils (Olivier \& Mesbah, 1986). An example is given in Fig. 6.

Some conclusions arrived at in applying this test are as follows.

(a) During compaction, the speed of the piston is an important factor if its average value is greater than $0.25 \mathrm{MPa} / \mathrm{s}$.

(b) The curves of dry density plotted against moisture content are similar to the Proctor curves and present an optimum which varies with the variation in compaction stress. However, when the moisture content is close to saturation point, the curve is generally flatter than the Proctor curve. In fact, where the stress is quasi-static the sample becomes saturated at a number of points and some of the moisture is discharged.

(c) This test is complemented by others which enable the resistance of the sample to be evaluated when it is stressed under different conditions: resistance under simple compression after compaction, resistance under simple compression after curing or after drying, resistance under tensile strength, and resistance after testing for capillary action, the latter test generally being applied to stabilized soils. It was shown that for a given compaction stress in all these instances the optimum resistance is obtained at optimum dry density (Olivier \& Mesbah, 1985, 1991).

(d) There is always a level of compaction stress which gives a compaction curve identical to
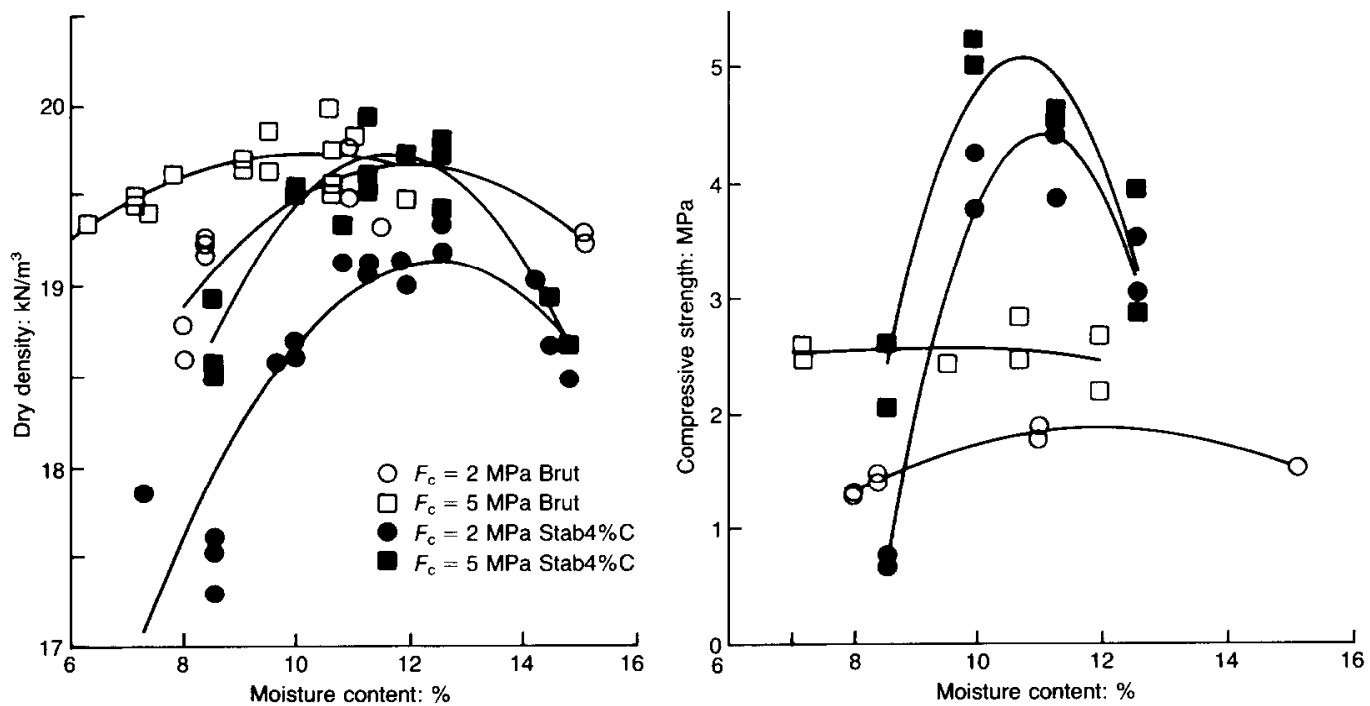

Fig. 6. Static compaction test: effect of compaction stress and treatment with $4 \%$ cement 
that obtained in the standard Proctor test, but this force varies with the grain size of the soil and the behaviour of the clay. A formula has been obtained from tests carried out on different soils which can be applied to soils of varying grain size which contain plastic clays (kaolin and illite)

$$
\begin{array}{r}
\sigma_{\mathrm{c}}=-2.221\left[10^{-9} w_{1}^{3}(\%<0.4 \mathrm{~mm})^{2} D_{\max }^{\prime}\right] \\
+5.18
\end{array}
$$

where $\sigma_{\mathrm{c}}$ is static compaction stress in $\mathrm{MPa}$ which gives a compaction curve identical to that in a standard Proctor test, $w_{1}$ is liquid limit, $(\%<0.4 \mathrm{~mm})$ is the percentage of grains smaller than $0.4 \mathrm{~mm}, D_{\max }^{\prime}$ is $D$ when $D<5 \mathrm{~mm}$ or when $D>5 \mathrm{~mm}$ and the percentage of grains smaller than $5 \mathrm{~mm}$ is greater than $10 \%$, and $D_{10}$ when the percentage of grains smaller than $5 \mathrm{~mm}$ is less than $10 \%, D$ being the maximum grain diameter. The value of $\sigma_{\mathrm{c}}$ varies from $0.5 \mathrm{MPa}$ to $5 \mathrm{MPa}$, higher values being obtained for very sandy or gravelly soils.

I have tried to use the results given in Fig. 3 to plot dry density against moisture content for different compaction stresses (Fig. 7), based on the assumption that the prepared samples were 76 $\mathrm{mm}$ cubes. The data given in the Paper are not sufficient to enable a complete compaction curve

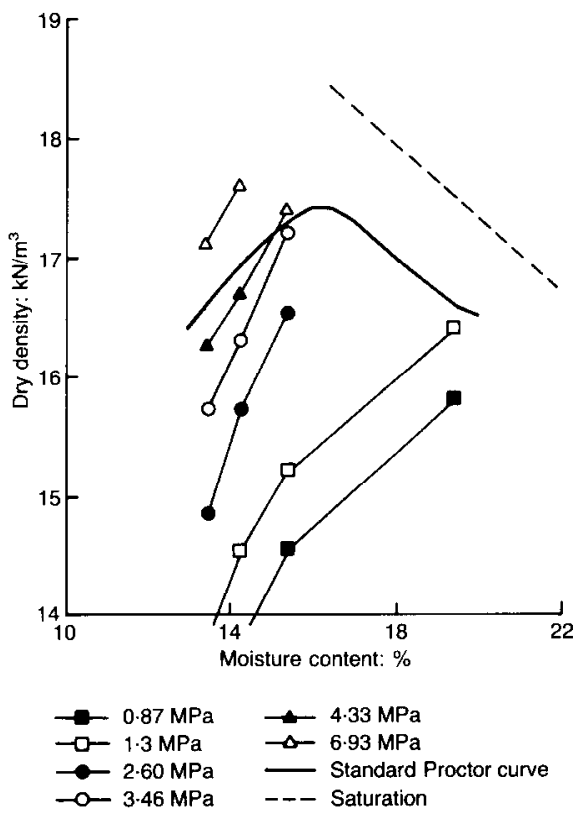

Fig. 7. Static compaction curves calculated from Fig. 3 to be drawn; however, Fig. 7 shows that the compaction curve for $4.33 \mathrm{MPa}$ is reasonably close to the standard Proctor curve.

Table 3 shows the energy (obtained by integration) for different levels of compaction for four values of moisture content. The energy obtained for $\left(\gamma_{d}, w\right)$ is slightly higher than that shown in Fig. 5, probably because of the imprecise values of $\Delta h$, which were obtained manually from Fig. 3 (see Tables 4-6).

Figure 8 shows the energy curves of Fig. 5 and the energy calculated along the compaction curve for $4.33 \mathrm{MPa}$. Along the static compaction curve, which equates to the standard Proctor curve, the energy absorbed by the soil is not constant: it decreases as the moisture content increases. This is due to the internal behaviour of the soil. On the dry side of the curve, the soil is mainly plastic and the pressure on the soil is totally absorbed by displacement of the grains. Depending on their structure and number, the grains are either displaced by force or cannot slide against each other. For this reason the dynamic or quasi-static stresses produce a greater density for the same amount of energy.

The greater the increase in moisture content, the more the free water in the soil acts as an elastic component of the behaviour of the soil. In

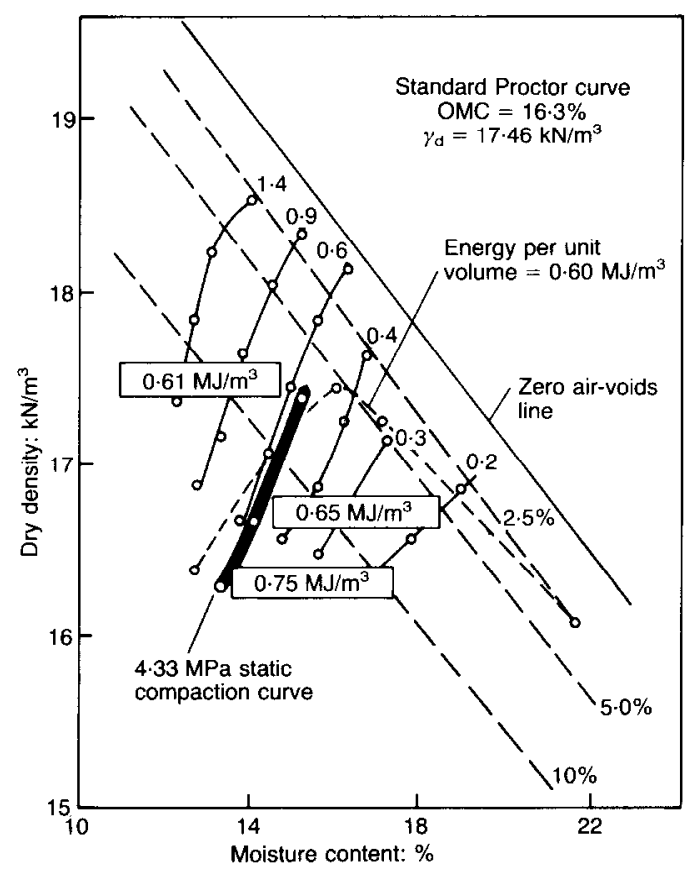

Fig. 8. Static compaction curve for $4 \cdot 33 \mathrm{MPa}$, and energy curves taken from Fig. 5 
DISCUSSION

Table 3. Evaluation of energy needed to compact soils with different levels of stress*

\begin{tabular}{l|c|c|c|c}
\hline \multirow{2}{*}{$\begin{array}{l}\text { Stress } \\
\text { MPa }\end{array}$} & \multicolumn{4}{|c}{ Energy: $\mathrm{MJ} / \mathrm{m}^{3}$} \\
\cline { 2 - 5 } & $w=13.05 \%$ & $w=14.31 \%$ & $w=15.45 \%$ & $w=19.42 \%$ \\
\hline 0 & 0 & 0 & 0 & 0 \\
0.43 & 0.085 & 0.100 & $0 \cdot 117$ & 0.157 \\
0.87 & 0.128 & 0.185 & 0.194 & 0.208 \\
1.30 & 0.228 & 0.256 & 0.251 & 0.251 \\
1.73 & 0.308 & 0.316 & 0.310 & 0.290 \\
2.60 & 0.393 & 0.430 & 0.424 & \\
3.46 & 0.592 & 0.550 & 0.504 & \\
4.33 & 0.746 & 0.652 & 0.607 & \\
5.19 & 0.943 & 0.891 & & \\
6.93 & 1.182 & 1.051 & & \\
8.66 & 1.489 & & & \\
\hline
\end{tabular}

* Energy is the area under the force-compaction stroke curve.

Table 4. Data used in calculations $\left(\gamma_{b}=20 \cdot 11 \mathrm{kN} / \mathrm{m}^{3}\right)$

\begin{tabular}{l|c|c|c|c}
\hline $\begin{array}{c}\text { Force: } \\
\mathbf{k N}\end{array}$ & \multicolumn{4}{|c}{$\Delta H: \mathrm{mm}$} \\
\cline { 2 - 5 } & $w=13 \cdot 5 \%$ & $w=14 \cdot 31 \%$ & $w=15 \cdot 45 \%$ & $w=19 \cdot 42 \%$ \\
\hline 0 & 0 & 0 & 0 & 0 \\
$2 \cdot 5$ & 30 & 35 & 41 & 55 \\
5 & 35 & 45 & 50 & 61 \\
$7 \cdot 5$ & 42 & 50 & 54 & 64 \\
10 & 46 & 53 & 57 & 66 \\
15 & 49 & 57 & 61 & \\
20 & 54 & 60 & 64 & \\
25 & 57 & 62 & 65 & \\
30 & 58 & 64 & & \\
40 & 61 & 66 & & \\
50 & 64 & & & \\
\hline
\end{tabular}

Table 5. Calculation of the dry density for each level $i$ of stress $\left(h_{\mathrm{fim}=1}=76 \mathrm{~mm}\right.$, $\left.\gamma_{d \text { dry final }}=\gamma_{\text {balk final }} /(1+w), \gamma_{b \text { bulk final }}=20 \cdot 11 \mathrm{kN} / \mathrm{m}^{3}\right)^{*}$

\begin{tabular}{|c|c|c|c|c|}
\hline$\gamma_{\mathrm{d} \text { dry final }}: \mathrm{kN} / \mathrm{m}^{3}$ & 17.79 & $17 \cdot 59$ & $17 \cdot 42$ & $16 \cdot 84$ \\
\hline \multirow{2}{*}{$\begin{array}{c}\text { Stress: } \\
\text { Mpa }\end{array}$} & \multicolumn{4}{|c|}{$\gamma_{d}(i): \mathrm{kN} / \mathrm{m}^{3}$} \\
\hline & $w=13 \cdot 5 \%$ & $w=14.31 \%$ & $w=15.45 \%$ & $w=19 \cdot 42 \%$ \\
\hline $\begin{array}{l}0 \\
0.433 \\
0.866 \\
1.298 \\
1.731 \\
2.597 \\
3.463 \\
4.328 \\
5 \cdot 194 \\
6.925 \\
8.657\end{array}$ & $\begin{array}{r}9.657 \\
12 \cdot 290 \\
12 \cdot 876 \\
13 \cdot 795 \\
14 \cdot 382 \\
14 \cdot 856 \\
15 \cdot 720 \\
16 \cdot 288 \\
16 \cdot 487 \\
17 \cdot 113 \\
17 \cdot 789\end{array}$ & $\begin{array}{r}9 \cdot 416 \\
12 \cdot 496 \\
13 \cdot 784 \\
14 \cdot 533 \\
15 \cdot 023 \\
15 \cdot 730 \\
16 \cdot 305 \\
16 \cdot 713 \\
17 \cdot 141 \\
17 \cdot 593\end{array}$ & $\begin{array}{r}9 \cdot 389 \\
13 \cdot 238 \\
14 \cdot 548 \\
15 \cdot 216 \\
15 \cdot 760 \\
16 \cdot 548 \\
17 \cdot 193 \\
17 \cdot 419\end{array}$ & $\begin{array}{r}9 \cdot 013 \\
14 \cdot 711 \\
15 \cdot 800 \\
16 \cdot 408 \\
16 \cdot 840\end{array}$ \\
\hline
\end{tabular}


DISCUSSION

Table 6. Calculation of the energy for each level of stress*

\begin{tabular}{|c|c|c|c|c|}
\hline \multirow{2}{*}{$\begin{array}{l}\text { Stress: } \\
\text { MPa }\end{array}$} & \multicolumn{4}{|c|}{ Energy: $\mathrm{MJ} / \mathrm{m}^{3}$} \\
\hline & $w=13 \cdot 05 \%$ & $w=14.31 \%$ & $w=15.45 \%$ & $w=19.42 \%$ \\
\hline $\begin{array}{l}0 \\
0 \cdot 433 \\
0 \cdot 866 \\
1 \cdot 298 \\
1 \cdot 731 \\
2.597 \\
3.463 \\
4 \cdot 328 \\
5 \cdot 194 \\
6 \cdot 925 \\
8 \cdot 657\end{array}$ & $\begin{array}{l}0 \\
0.085 \\
0.128 \\
0.228 \\
0.308 \\
0.393 \\
0.592 \\
0.746 \\
0.943 \\
1.182 \\
1.489\end{array}$ & $\begin{array}{l}0 \\
0 \cdot 100 \\
0.185 \\
0.256 \\
0.316 \\
0.430 \\
0.550 \\
0.652 \\
0.891 \\
1.051\end{array}$ & $\begin{array}{l}0 \\
0.117 \\
0.194 \\
0.251 \\
0.310 \\
0.424 \\
0.504 \\
0.607\end{array}$ & $\begin{array}{l}0 \\
0 \cdot 157 \\
0 \cdot 208 \\
0 \cdot 251 \\
0 \cdot 290\end{array}$ \\
\hline
\end{tabular}

* Energy is the area under the force-compaction stroke curve.

dynamic tests when the soil contains a certain amount of clay the dissipation of energy can be felt in the vibrations of the test equipment and sometimes through the floor of the laboratory. When the stress is applied statically, the grains are displaced by force and move closer together, and simultaneously the free water is forced into the pores of the soil. In this case, if the piston stroke is slow enough, this water can be displaced and the force needed to achieve a specific compaction level is lower than under dynamic compaction.

Tests were also carried out on the soil containing plastic clay which had $D=5 \mathrm{~mm}, 56 \%$ of grains smaller than $0.4 \mathrm{~mm}, 8 \%$ smaller than 2 $\mu \mathrm{m}$, a liquid limit of 42 and a plastic limit of 22.3 (Olivier, 1994).

Equation (1) gives a stress equivalent to the standard Proctor test of $4 \mathrm{MPa}$. Fig. 9 shows the compaction curves for this material for stresses of $2-11.5 \mathrm{MPa}$, as well as for the displacement of the piston as a function of the stress. There is also fairly good agreement between the Proctor curve and the static compaction curve of $4 \mathrm{MPa}$. The force measured along the latter curve gives the results shown in Table 7 . With a stress of $4 \mathrm{MPa}$, the soil was compacted to the standard Proctor level, but far less encrgy was required to produce
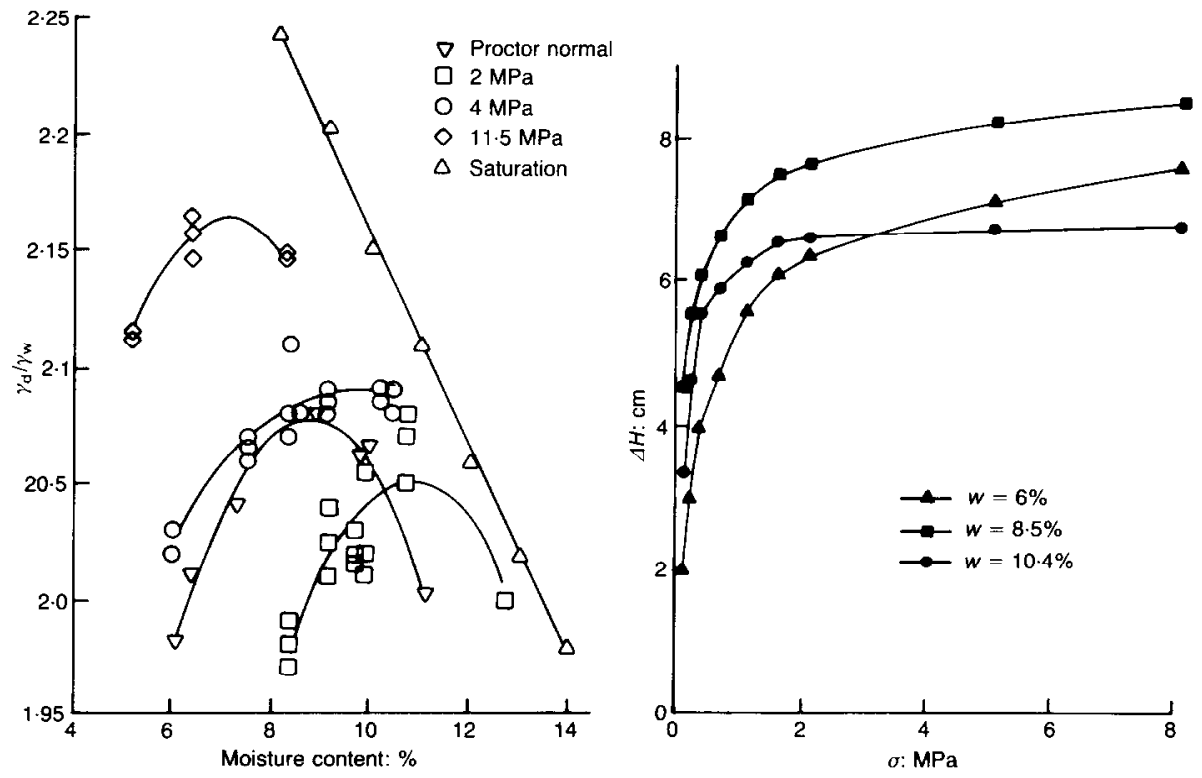

Fig. 9 
Table 7. Calculation of compaction energy $\left(\mathrm{MJ} / \mathrm{m}^{3}\right)$ for two values of compaction stress*

\begin{tabular}{|c|c|c|c|c|c|c|c|c|c|c|}
\hline Moisture content: $\%$ & \multicolumn{2}{|c|}{6} & \multicolumn{3}{|c|}{$8 \cdot 3$} & \multicolumn{2}{|c|}{$8 \cdot 5$} & \multicolumn{3}{|c|}{$10 \cdot 4$} \\
\hline $\begin{array}{l}\gamma_{\mathrm{d}}: \mathrm{kN} / \mathrm{m}^{3}\left(F_{\mathrm{c}}=4 \mathrm{MPa}\right) \\
\text { Energy: } \mathrm{MJ} / \mathrm{m}^{3}\end{array}$ & $\begin{aligned} 20 \cdot 27 \\
0-494\end{aligned}$ & $\begin{array}{r}20 \cdot 22 \\
0 \cdot 474\end{array}$ & $\begin{array}{c}21 \cdot 07 \\
0.332\end{array}$ & $\begin{array}{c}20 \cdot 71 \\
0 \cdot 297\end{array}$ & $\begin{array}{c}20 \cdot 81 \\
0 \cdot 319\end{array}$ & $\begin{array}{r}20 \cdot 83 \\
0.31\end{array}$ & $\begin{array}{r}20 \cdot 8 \\
0.35\end{array}$ & $\begin{array}{c}20 \cdot 84 \\
0 \cdot 143\end{array}$ & $\begin{array}{c}20.89 \\
0.162\end{array}$ & $\begin{array}{r}20 \cdot 88 \\
0 \cdot 123\end{array}$ \\
\hline$\gamma_{\mathrm{d}}: \mathrm{kN} / \mathrm{m}^{3}\left(F_{\mathrm{c}}=8 \mathrm{MPa}\right)$ & $21 \cdot 08$ & $21 \cdot 1$ & $21 \cdot 59$ & $21 \cdot 3$ & $21 \cdot 3$ & $21 \cdot 4$ & 21.4 & 21 & 21 & 21 \\
\hline Energy: $\mathrm{MJ} / \mathrm{m}^{3}$ & 0.733 & 0.736 & $0 \cdot 48$ & 0.47 & $0 \cdot 46$ & $0-45$ & 0.52 & $0 \cdot 187$ & 0.195 & $0 \cdot 157$ \\
\hline
\end{tabular}

* $\gamma_{\mathrm{d}}$ final dry density, $F_{\mathrm{c}}$ compaction stress.

blocks of compressed soil and it was shown that

(a) with each type of piston stroke delivering a given value of stress, it is very important to evaluate the optimum moisture content which corresponds to the stroke and to the soil

(b) to obtain a certain density, static compression generally requires a level of energy lower than that for dynamic compaction.

There seems to be an error in Table 2. For soil 3 , with a moisture content of $14.47 \%$, a dry density of $17.66 \mathrm{kN} / \mathrm{m}^{3}$ is equivalent to a compaction energy of about $0.8 \mathrm{MJ} / \mathrm{m}^{3}$ (Fig. 5), not $0.384 \mathrm{MJ} / \mathrm{m}^{3}$. Similarly, for a moisture content of $11.6 \%$ the compaction energy shown in Fig. 5 seems to be much greater at $1.4 \mathrm{MJ} / \mathrm{m}^{3}$.

\section{Authors' reply}

Mrs Olivier has attempted to compare her constant stress compaction test with the static compaction test we developed. The compaction curve reported in the Paper is also a constant energy curve like the well-known Proctor curve. The Paper distinguishes between constant peak stressvariable stroke compaction and variable peak stress-constant stroke compaction. If the results of a laboratory test are to be related to what happens in a compaction operation at the site, energy used in compaction per unit volume is probably a more useful parameter. This explains our choice of the latter technique. Mrs Olivier apparently argues that stress is a better parameter. If the same stress is operating for a longer duration the compactive effort could be more and this could lead to anomalies in the interpretation.

However, she agrees with our conclusion that static compaction generally requires less energy than dynamic compaction and also comments that the energy in Table 2 is less than the energy reported in Fig. 5. The soil used to examine size effect proved to be different although it was procured from the same site. This soil was $47 \%$ clay, $10 \%$ silt and the rest was sand. The lower energy absorption is due to the higher clay content.

\section{REFERENCES}

Olivier, M. (1994). Le matériau terre-compactage, comportement, application aux structures en blocs de terre. PhD thesis, Institut National des Sciences Appliquées, Lyon.

Olivier, M. \& Mesbah, A. (1985). Caractérisation des briques de terre crue compressées par l'essai Proctor statique. Vaulx en Velin: Ecole Nationale des Travaux Publics de l'Etat.

Olivier, M. \& Mesbah, A. (1986). Le Matériau terrel'essai de compactage statique pour la fabrication de briques de terre crue compressées. Bull. Liais. Labs Ponts Chauss., No. 146, Nov.-Dec., 37-43.

Olivier, M. \& Mesbah, A. (1991). Comportement des matériaux fins, en géotechnique routière. Proc. 19th Wld Rd Congr., Marrakech, 522523. 